\title{
Improvement of Desirable Thermophysical Properties of Soybean Oil for Metal Cutting Applications as a Cutting Fluid
}

Putta Nageswara Rao*,1, Suresh Babu Valer ${ }^{2}$, Koka Naga Sai Suman ${ }^{2}$

${ }^{1}$ Department of Mechanical Engineering, VVIT, Guntur, 522508, India.

${ }_{2}^{2}$ Department of Mechanical Engineering, Andhra University, Visakhapatnam, 53000, India.

\begin{tabular}{l} 
A R T I C L E I N F O \\
\hline Article history: \\
Received: 09 March, 2020 \\
Accepted: 14 April, 2020 \\
Online: 03 May, 2020 \\
\hline Keywords: \\
Soybean oil \\
Reduced graphene oxide \\
Al $_{2} \mathrm{O}_{3}$ \\
Nanoparticle concentration \\
Properties \\
Stability
\end{tabular}

\section{Introduction}

Vegetable oils are widely used as a cutting fluid for machining applications from last two decades because of their high lubrication performance, less toxicity, eco-friendly and nonhazardous nature. However, during the real time applications especially concerned to machining applications performance of these oils differs one over the other due to the wide variation of fluid properties [1-3]. Therefore Suresh et.al [4] investigated about optimization of vegetable oil properties through CFD and established that thermal conductivity and viscosity play a major role in improving the machining performance apart from another two important properties such as specific heat and density. Within their studies [4] they further established that viscosity ( $\mathrm{kg} / \mathrm{m} . \mathrm{s})$, Density $\left(\mathrm{kg} / \mathrm{m}^{3}\right)$, Thermal conductivity $(\mathrm{w} / \mathrm{m}-\mathrm{k})$ and Specific heat (J/kg-k) 0.025, 920, 0.18 and 2000 respectively are the desirable thermo physical properties required for a vegetable oil for

\footnotetext{
*Nageswara Rao putta, Department of Mechanical Engineering, VVIT, Guntur, 522508, India, ph.no: +919949001586 \& Email: vvitpnr@gmail.com.

imparting better machining performance. However, within the literature [5-6] it is further observed that among various vegetable oils, soybean oil is found to be better [7] and has the scope for the researchers to improve its thermophysical properties nearer to optimized values established by Suresh et.al [4].

Therefore the present work focuses on improving the thermophysical properties of soybean oil by reinforcement of widely used metallic $\left(\mathrm{Al}_{2} \mathrm{O}_{3}\right)$ nanoparticles [8-9] and nonmetallic RGO[10-11] nanoparticles as separate combinations and ascertaining the better category of nanoparticles and its concentration which can impart the desirable properties and also can give long term usage capability.

\section{Materials}

Within the present work the base vegetable oil i.e soybean was purchased from local market and nanoparticles such as reduced graphene oxide and aluminum oxide nanoparticles was procured 
from Aarshadhatu green nanotechnologies India private limited, Guntur.

All the procured materials were commercial grade and do not require any further purification.

\section{Preparation of nanofluids and evaluation their properties}

Initially within the present work it is intended to prepare nanofluid samples containing metallic and non-metallic particles with various concentrations and their properties are to be evaluated day after day. Apart from this it is also intended to observe the suspension phenomena of nanoparticles within the base fluid through sedimentation analysis.

\subsection{Nanofluid preparation}

Nano fluid samples were prepared using two step method. For this soybean oil as taken as a base fluid for separate dispersion of reduced graphene oxide and $\mathrm{Al}_{2} \mathrm{O}_{3}$ nanoparticles at different weight percentage $(0.25,0.5,0.75$ and $1 \%)$ combinations ranging from $0.25-1 \%$ insteps of $0.25 \%$. Afterwards the solution was mixed by bath sonicator upto 60 minutes of duration at room temperature. Prepared samples were shown through figure 1.

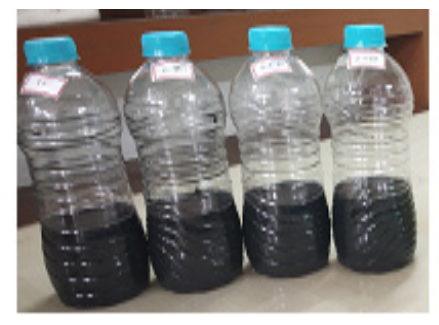

(a)

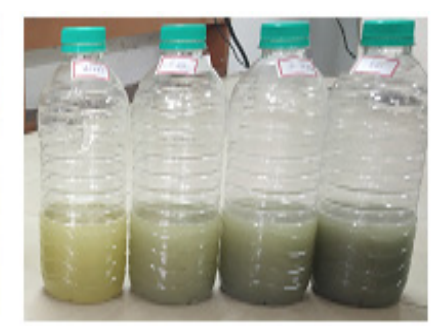

(b)
Figure 1: Prepared nanofluid at different concentrations (a) RGO contained Soybean (b) $\mathrm{Al}_{2} \mathrm{O}_{3}$ contained Soybean

\subsection{Properties evaluation}

Since the present oil is intended as lubricating oil for machining applications therefore major important properties i.e thermal conductivity has been found out through KD2 pro thermal conductivity analyzer, viscosity through Brookfield viscometer, density through Anton Parr density meter and specific heat through nanofluid heat capacity apparatus day by day upto 6 days after the preparation of nanofluid. The obtained properties were tabulated through Table $1 \& 2$ at alternate two days.

Table 1: Measured Properties of $\mathrm{Al}_{2} \mathrm{O}_{3}$ suspended nanofluid samples

\begin{tabular}{|c|c|c|c|c|c|c|c|c|c|c|c|c|}
\hline \multirow[b]{3}{*}{ Properties } & \multicolumn{12}{|c|}{ Weight percentage concentrations } \\
\hline & \multicolumn{3}{|l|}{$0.25 \%$} & \multicolumn{3}{|l|}{$0.5 \%$} & \multicolumn{3}{|l|}{$0.75 \%$} & \multicolumn{3}{|l|}{$1 \%$} \\
\hline & $\begin{array}{l}\text { Day } \\
2\end{array}$ & $\begin{array}{l}\text { Day } \\
4\end{array}$ & $\begin{array}{l}\text { Day } \\
6\end{array}$ & $\begin{array}{l}\text { Day } \\
2\end{array}$ & $\begin{array}{l}\text { Day } \\
4\end{array}$ & $\begin{array}{l}\text { Day } \\
6\end{array}$ & $\begin{array}{l}\text { Day } \\
2\end{array}$ & $\begin{array}{l}\text { Day } \\
4\end{array}$ & $\begin{array}{l}\text { Day } \\
6\end{array}$ & $\begin{array}{l}\text { Day } \\
2\end{array}$ & $\begin{array}{l}\text { Day } \\
4\end{array}$ & $\begin{array}{l}\text { Day } \\
6\end{array}$ \\
\hline Thermal conductivity (w/mk) & 0.168 & 0.168 & 0.166 & 0.172 & 0.172 & 0.167 & 0.176 & 0.176 & 0.175 & 0.181 & 0.180 & 0.176 \\
\hline Viscosity(cst) & 27.8 & 27.8 & 27.5 & 28.1 & 28.1 & 28.0 & 28.5 & 28.5 & 28.3 & 29.0 & 29.0 & 28.8 \\
\hline Specific Heat(j/kg.k) & 1.979 & 1.979 & 1.975 & 1.981 & 1.981 & 1.979 & 2.108 & 2.108 & 2.103 & 2.119 & 2.119 & 2.211 \\
\hline $\operatorname{Density}\left(\mathrm{g} / \mathrm{cm}^{3}\right)$ & 0.917 & 0.916 & 0.916 & 0.923 & 0.923 & 0.920 & 0.923 & 0.923 & 0.921 & 0.930 & 0.929 & 0.929 \\
\hline
\end{tabular}

Table.2: Measured Properties of RGO suspended nanofluid samples

\begin{tabular}{|c|c|c|c|c|c|c|c|c|c|c|c|c|}
\hline \multirow{3}{*}{ Properties } & \multicolumn{12}{|c|}{ Weight percentage concentrations } \\
\hline & \multicolumn{3}{|c|}{$0.25 \%$} & \multicolumn{3}{|l|}{$0.5 \%$} & \multicolumn{3}{|c|}{$0.75 \%$} & \multicolumn{3}{|l|}{$1 \%$} \\
\hline & $\begin{array}{l}\text { Day } \\
2\end{array}$ & $\begin{array}{l}\text { Day } \\
4\end{array}$ & $\begin{array}{l}\text { Day } \\
6\end{array}$ & $\begin{array}{l}\text { Day } \\
2\end{array}$ & $\begin{array}{l}\text { Day } \\
4\end{array}$ & $\begin{array}{l}\text { Day } \\
6\end{array}$ & $\begin{array}{l}\text { Day } \\
2\end{array}$ & $\begin{array}{l}\text { Day } \\
4\end{array}$ & $\begin{array}{l}\text { Day } \\
6\end{array}$ & $\begin{array}{l}\text { Day } \\
2\end{array}$ & $\begin{array}{l}\text { Day } \\
4\end{array}$ & $\begin{array}{l}\text { Day } \\
6\end{array}$ \\
\hline Thermal conductivity $(\mathrm{w} / \mathrm{mk})$ & 0.172 & 0.172 & 0.171 & 0.181 & 0.181 & 0.180 & 0.187 & 0.186 & 0.185 & 0.190 & 0.190 & 0.187 \\
\hline Viscosity(cst) & 27.9 & 27.9 & 27.6 & 28.3 & 28.3 & 28.1 & 28.7 & 28.7 & 28.4 & 29.2 & 29.2 & 29.0 \\
\hline Specific Heat(j/kg.k) & 1.982 & 1.982 & 1.980 & 2.018 & 2.018 & 2.090 & 2.185 & 2.182 & 2.138 & 2.228 & 2.219 & 2.211 \\
\hline $\operatorname{Density}\left(\mathrm{g} / \mathrm{cm}^{3}\right)$ & 0.918 & 0.918 & 0.916 & 0.921 & 0.921 & 0.919 & 0.923 & 0.923 & 0.921 & 0.928 & 0.928 & 0.927 \\
\hline
\end{tabular}


From the above obtained results, the variation of properties of the prepared nanofluid samples were analysed in the following sections.

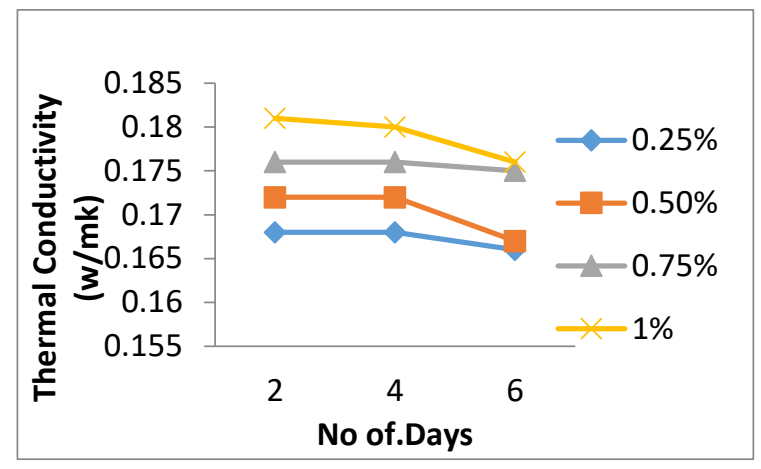

(a) Thermal Conductivity

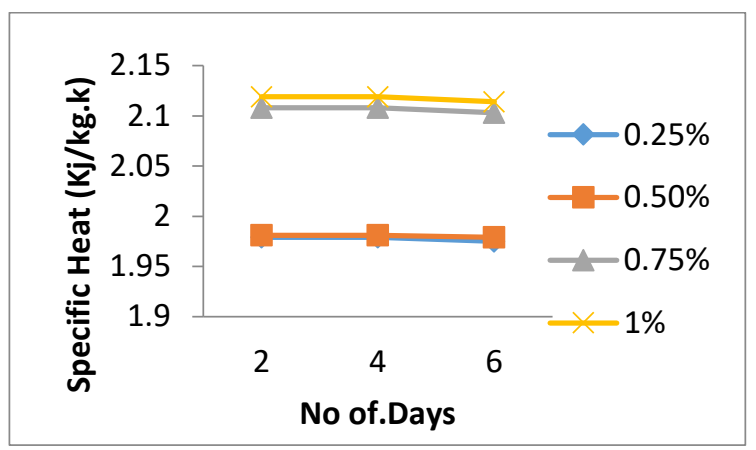

(c) Specific Heat

\subsection{Variation of properties}

From the obtained values of various properties of the different nanofluids at different concentrations the variation properties were plotted with respect to number of days and are shown Figures $2 \& 3$.

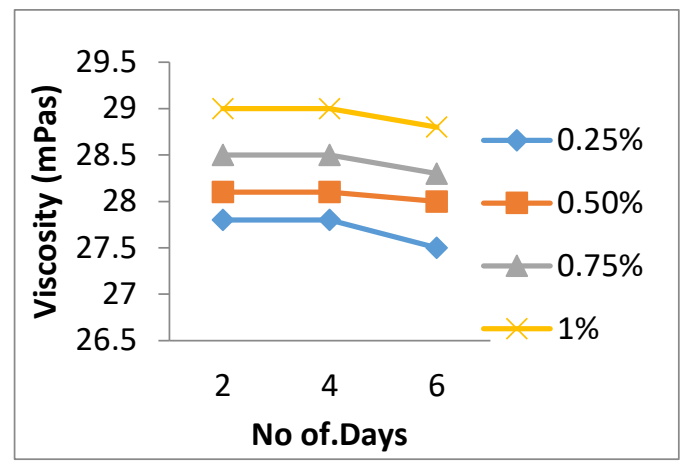

(b) Viscosity

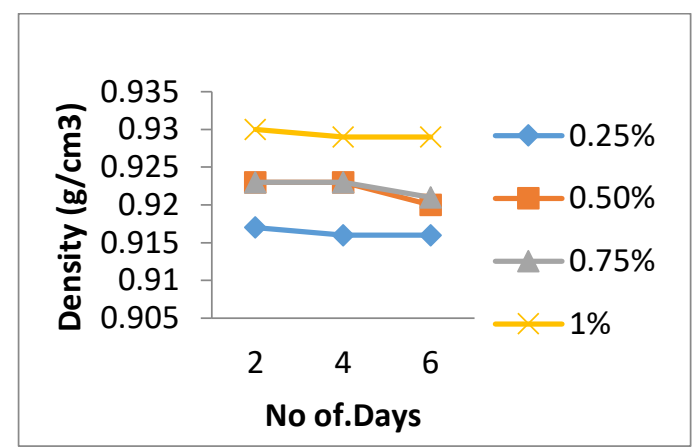

(d) Density

Figure 2: Variation of thermophysical properties of $\mathrm{Al}_{2} \mathrm{O}_{3}$ suspended soybean oil w.r.t to no.of days

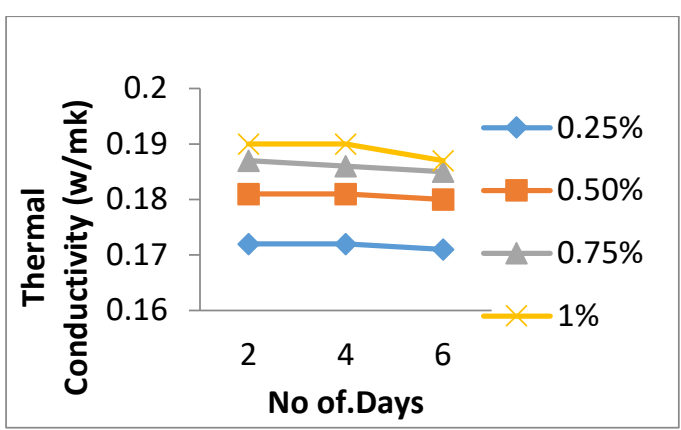

(a) Thermal Conductivity

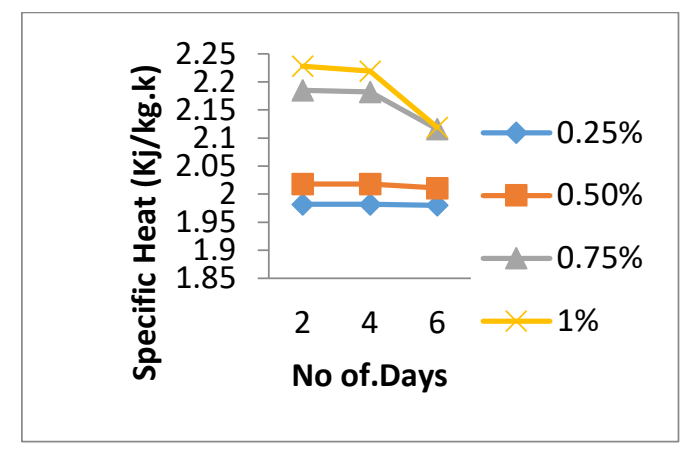

(c) Specific Heat

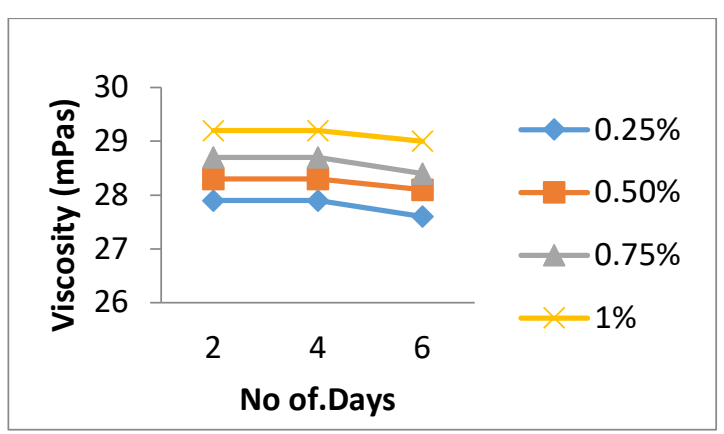

(b) Viscosity

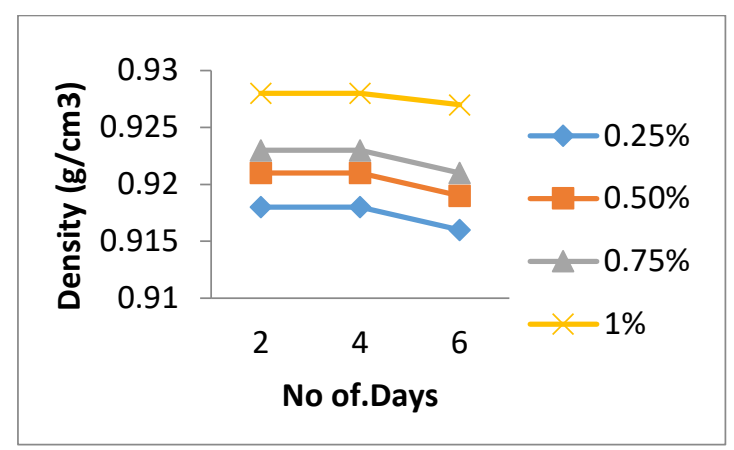

(d) Density

Figure 3: Variation of thermophysical properties of RGO suspended soybean oil w.r.t to no.of days 


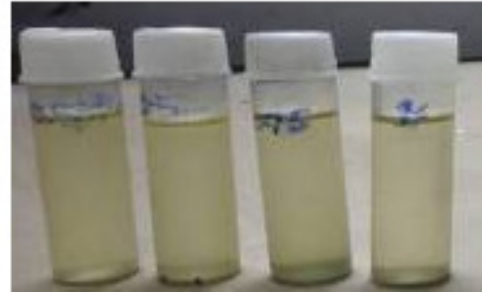

(a)

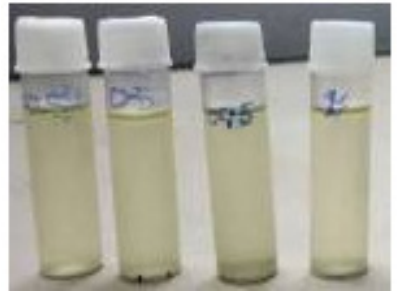

(b)

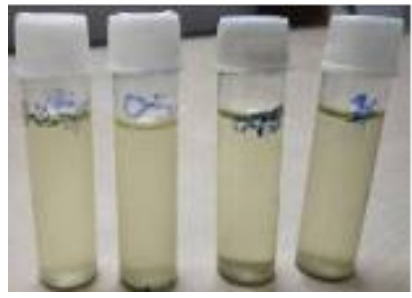

(c)

Figure 4: Digital photographs of $\mathrm{Al}_{2} \mathrm{O}_{3}$ /soybean nanofluid at different concentrations a) 2 days time of preparation b) After 4 days preparation. c) After 6 days of preparation

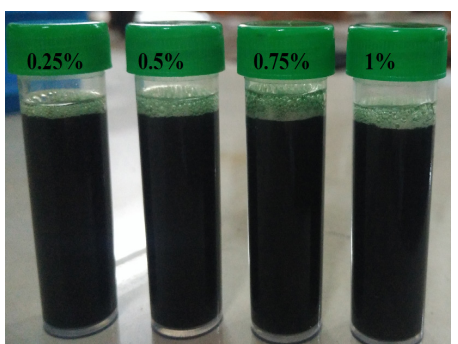

(a)

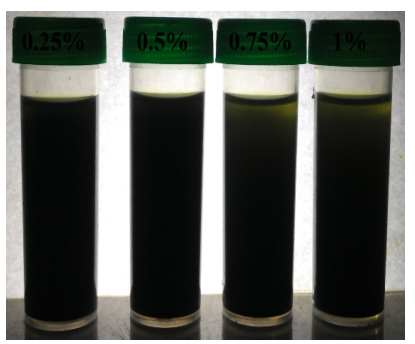

(b)

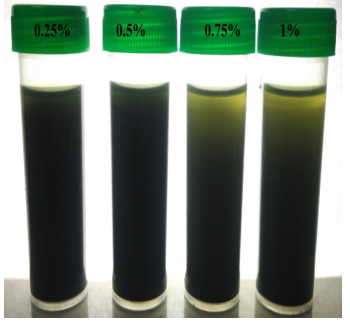

(c)

Figure 5: Digital photographs of RGO/soybean nanofluid at different concentrations a) 2 days time of preparation b) After 4 days preparation. c) After 6 days of preparation

Generally, nanofluids has higher properties than the corresponding base oils due to their random drifting of suspended nanoparticles in the base fluid and nanoparticles are compared to more thermophysical properties than liquids which originates from collisions between the nanoparticles and liquid molecules and the same trend was observed in the present work. From the figures $2 \& 3$ it was observed that with the increase of particle concentration all the measured properties are found to be increasing after $2 \mathrm{nd}$ and up to the 4 th day of preparation however after 4 days of preparation all the properties at 0.75 and 1 weight percentage combinations gradually decreased but at $0.5 \%$ concentration the properties were found to be constant.

Observing the individual trend of prepared nanofluid samples containing $\mathrm{Al}_{2} \mathrm{O}_{3}$ and $\mathrm{RGO}$ it is observed that RGO suspended nanofluid samples exhibited superior properties compared $\mathrm{Al}_{2} \mathrm{O}_{3}$ suspended samples. The superiority of RGO suspended nanofluid samples compared to $\mathrm{Al}_{2} \mathrm{O}_{3}$ suspended samples can be attributed to better stability and interaction of RGO particles with the base fluid compared to $\mathrm{Al}_{2} \mathrm{O}_{3}$ particles.It is further observed that at $0.5 \%$ concentration of $\mathrm{RGO}$ the properties tend to be much more stable compared to other concentrations and more importantly the obtained properties were nearer to the optimized values established by Suresh et.al [4].

\subsection{Visualization effect}

Figures $4 \& 5$ shows the photos of different weight percentage concentrations of $\mathrm{Al}_{2} \mathrm{O}_{3}$-susupended and $\mathrm{RGO}$ suspended soybean oil samples taken after 2, 4 and 6 for visual inspection. From the visual inspection it is observed that the sedimentation was found to very less for all the concentrations after the preparation of oil up to two days after that with the increase in time it was found to be increasing at all concentrations with in which 0.75 and $1 \%$ weight percent of nanoparticles led to high sedimentation compared to 0.25 and $0.5 \%$ weight concentration.

\section{Stability improvement through ultrasonication}

Based on the obtained thermophysical properties and the studies carried out through visualization it is concluded that RGO suspended nanofluid at $0.5 \%$ weight concentration has resulted for imparting the desirable properties established by suresh et.al [4]. Since the prepared nanofluid intended for using as a lubricant in machining applications, apart from desirable properties it further required to have long term stability therefore within the present work the prepared $0.5 \%$ wt RGO nanofluid samles were subjected to ultrasonication for imparting better stability to the nanoparticles. Ultrasonication was carried out for a durations $60-$ 180 minutes insteps of $30 \mathrm{~min}$. thereby in total five ultrasonicated nanofluid samples have been prepared and the samples were evaluated for their thermal conductivity and viscosity which are most influencing properties.

\subsection{Variation of properties after ultrasonication}

The thermal conductivity of the nanofluid of prepared nanofluid and their variations at different ultrasonication durations with respect to number of days plotted as shown in Figure 6. With the different ultrasonication durations of RGO-soybean oil thermal conductivity is found to be increasing after 60 minutes to 120 minutes ultrasonication durations upto 20 days of preparation. However, after 120 minutes ultrasonication thermal conductivity at 150 and 180 minutes gradually decreased but at 120 minutes of durations the stability of nanoparticles was found to be stable upto 20 days of preparation. The same trend was observed in viscosity of nanofluid which is from Figure 7. 


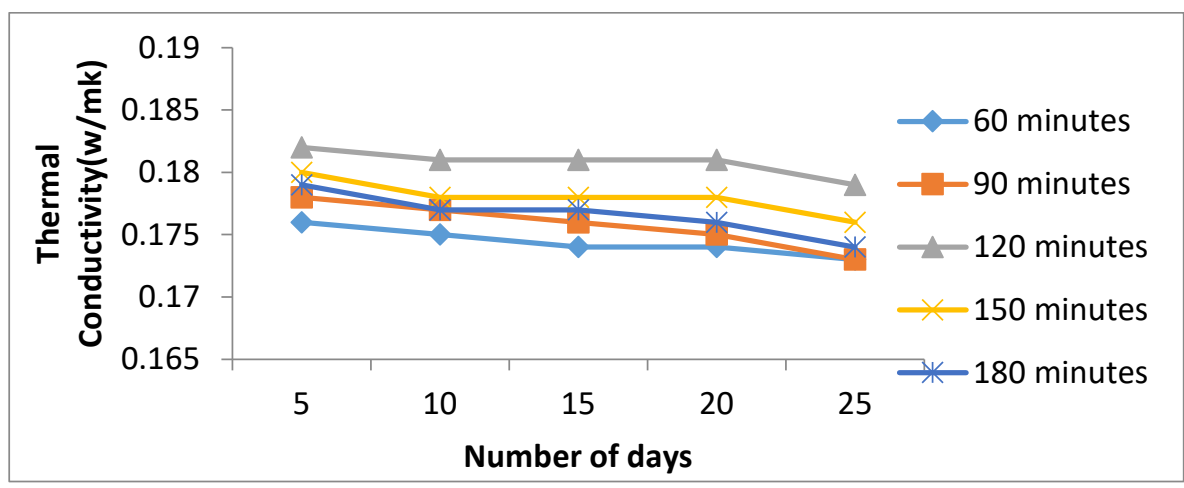

Figure 6: Variation of thermal conductivity with respect to number of days

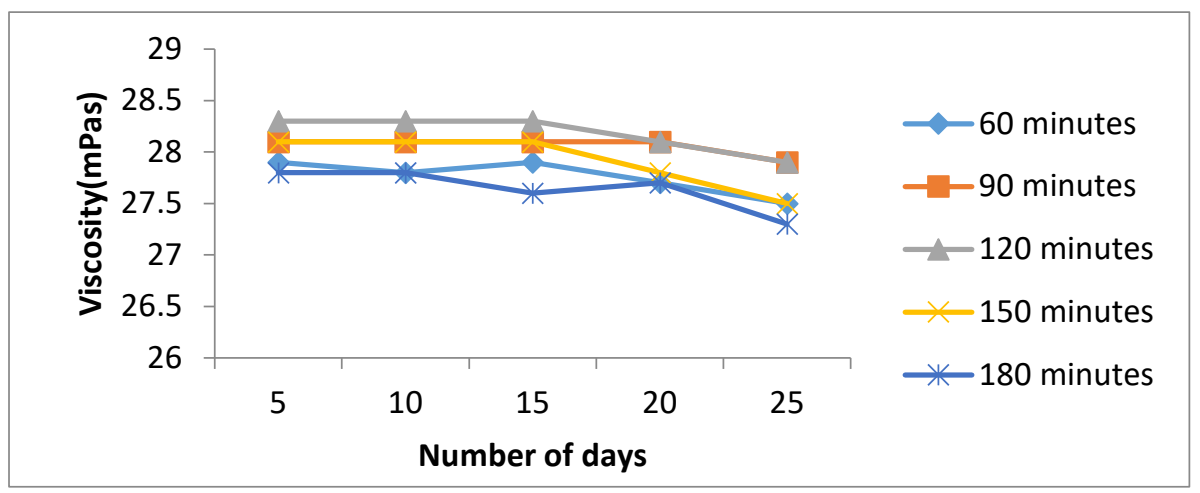

Figure 7: Variation of viscosity with respect to number of days

From the results it is observed that increasing ultrasonication duration of $120 \mathrm{~min}$, dispersity of nanoparticles became more even and homogeneous, and presence of agglomerates diminished significantly. This is attributed due to the fact that ultrasonic energy broke down the nanoparticle agglomerations, and it could yield a more homogeneous nanofluid sample. On the other hand, further increase of ultrasonication period resulted in a slight tendency for re-agglomeration, re-agglomeration of particles with the latter sonication period may be seen.

\subsection{Visualization effect of nanofluid with ultrasonication}

Figure 8(a)-(b) exhibit the sedimentation pictures of reduced graphene oxide-soybean nanofluid samples prepared at different ultrasonic durations and after the 20 and 25 days of preparation

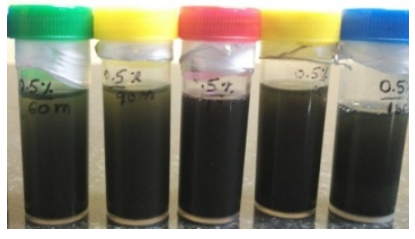

(a) After 20 days

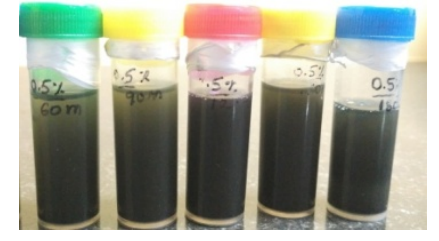

(b) After 25 days
Figure 8: Digital photographs of prepared nanofluid samples at different ultrasonication durations of 60-180 minutes insteps of 30 minutes

From the visual analysis it is observed that the sedimentation rate was found to very less for all the concentrations after the preparation of oil upto 20 days after that with increase in time the rate was found to be increasing at all ultrasonic durations except for 120 minutes where the sedimentation rate was found to be very less.

\section{Conclusions}

The present work mainly concentration about preparation of soybean based nanofluid containing the thermophysical properties [4] required for improving machining performance and also for long term usage with required properties. Based on the above aims the following conclusion has been drawn.

- Reinforcement of $\mathrm{Al}_{2} \mathrm{O}_{3}$ and $\mathrm{RGO}$ nanoparticles into the base fluid has resulted for enhancement of required properties considerably.

- Compared to metallic $\mathrm{Al}_{2} \mathrm{O}_{3}$ nanoparticles, non-metallic RGO nanoparticles has resulted for bringing the thermophysical properties upto the desired level compared to metallic nanoparticles.

- It is observed that nanoparticles at $0.5 \%$ RGO nanoparticles concentration have resulted for bringing for the properties upto the desired level.

- After that ultrasonic treatment of nanofluid with $0.5 \%$ RGO has resulted for long term stability of nanoparticles up to 20 days without having much variation in the thermophysical properties.

\section{References}

[1] Susmitha, Sharan, Jyothi, "Influence of non-edible vegetable based oil as cutting fluid on chip, surface roughness and cutting force during drilling operation of mild steel" in IOP Conf. Series: Materials Science and Engineering,2016, doi:10.1088/1757-899X/149/1/012037.

[2] Sunday Albert Lawal' Imtiaz Ahmed Choudhury, Ibrahim Ogu, Sadiq, Adedipe, Oyewole, "Vegetable-oil based metalworking fluids research developments for machining processes: survey, applications and challenges" in Manufacturing Rev., Volume 1, 2014. 
[3] Surase, Pawar, Ramkisan, "Performance of vegetable oil based cutting fluid in machining of steel by using MQL -A review" Lubricants, Volume 5, Issue 44,2017, doi:10.3390/lubricants5040044.

[4] Suresh Babu Valeru, Nageswara Rao, K.N.S Suman, "Optimization of vegetable oil properties in machining environment through CFD" in International Journal of Innovative Technology and Exploring Engineering (IJITEE) ISSN: 2278-3075, Volume-8 Issue-12. 2019.

[5] Karmakar Gobind, Ghosh Pranab, Sharma Brajendra, "Chemically modifying vegetable oils to prepare green lubricant"inLubricants.5,2017,doi:10.3390/lubricants5040044.

[6] Shrikant Madiwale, Virendra Bhojwani, "An overview on production, properties, performance and emission analysis of blends of biodiesel" in Procedia Technology 25, 2016.

[7] Putta Nageswara Rao, Suresh Babu Valeru, Koka Naga Sai Suman, "Selection of vegetable oil for MQL as a cutting fluid through MADM methods" Accepted in industrial engineering journal, Paper Id:1246.

[8] Vasheghani Mohammadhassan, Marzbanrad, Ehsan, Zamani Cyrus, Aminy Mohammad, "Effect of $\mathrm{Al}_{2} \mathrm{O}_{3}$ phases on the enhancement of thermal conductivity and viscosity of nanofluids in engine oil" in Heat and Mass Transfer 47,2011.

[9] Rahman Mostafizur, Rahman Saidur, Abdul Raman, Abdul Aziz, "Thermophysical properties of methanol based $\mathrm{Al}_{2} \mathrm{O}_{3}$ nanofluids" in International Journal of Heat and Mass Transfer 85,2015.

[10] Syed Nadeem, Abbas Shah, Syed Shahabuddin, Mohd Faizul Mohd Sabri, Mohd Faiz Mohd Salleh, "Experimental investigation on stability, thermal conductivity and rheological properties of $\mathrm{rGO} /$ ethylene glycol based nanofluids" in International Journal of Heat and Mass Transfer, Volume 150, 2020.

[11] Kamatchi, Kannan Gopi, "An Aqua based reduced graphene oxide nanofluids for heat transfer applications: synthesis, characterization, stability analysis, and thermophysical properties" in International Journal of Renewable Energy Research. 8, 2018. 